\title{
Reference values for the six-minute walk test in Nigerian adolescents aged 10 to 18 years
}

\author{
*Abdulkadir, M.B. ${ }^{1,2}$, Ibraheem, R.M. ${ }^{1,2}$, Akintade, O.O. ${ }^{2}$, Suberu, H.D. ${ }^{2}$, Issa, A. ${ }^{2}$, \\ Alabi, K. ${ }^{2}$
}

\begin{abstract}
Objective: To determine baseline six-minute walk distance in Nigerian adolescents and establish its relationship with age, gender and anthropometric parameters.
\end{abstract}

Methods: One hundred and eighty healthy adolescents ( $10-18$ years) were recruited from three schools. Six-minute walk test was conducted as described by the American Thoracic Society. Demographic and anthropometric characteristics were related to achieve six-minute walk distance. A mathematical formula for predicting six-minute walk distance was generated.

Results: The mean \pm SD six-minute walk distance was $590.1 \pm 72.02 \mathrm{~m}$ and was significantly longer in males $(p=0.001)$ among adolescents aged $10-16$ years. Age was the only characteristic significantly associated with six-minute walk distance following multiple linear regression analyses. The formulae, [six-minute walk distance $=317.3+21.5 \mathrm{x}$ age (years) in males and $117+33.0 \mathrm{x}$ age (years) in females] closely approximated to measured six-minute walk distance.

Conclusion: This study has derived reference values for 6-minute walk test in adolescents; the use of these reference values should consider age and gender variations.

Keywords: Exercise test; Six-minute-walk; Adolescents; Nigeria

\author{
*Corresponding author \\ Abdulkadir, M.B. \\ http://orcid.org/0000- \\ Email address: docmohng@gmail.com
}

\footnotetext{
${ }^{1}$ Department of Paediatrics and Child Health, University of Ilorin, Ilorin, Nigeria

${ }^{2}$ Department of Paediatrics and Child Health, University of Ilorin Teaching Hospital, Ilorin, Nigeria
} 


\title{
Valeurs de Référence Pour le Test de la Promenade de Six (6) Minutes chez des Adolescents Nigérians Agés de 10 à 18 ans
}

\author{
*Abdulkadir, M.B. ${ }^{1,2}$, Ibraheem, R.M. ${ }^{1,2}$, Akintade, O.O. ${ }^{2}$, Suberu, H.D. ${ }^{2}$, Issa, A. ${ }^{2}$ \\ Alabi, $\mathrm{K}^{2}$
}

\section{Résumé}

Objectif de l'étude: Déterminer la ligne de base de six minutes de la distance de la promenade chez les adolescents nigérians et établir sa relation avec l'âge, le sexe et les paramètres anthropométriques.

Méthode de l'étude: 180 adolescents en bonne santé (âgés de 10 à 18 ans) ont été recrutés dans trois écoles. Le test de la promenade en six minutes a été réalisé comme décrit par La Société Américaine Thoracique. Les caractéristiques démographiques et anthropométriques étaient liées à la distance de la promenade obtenue en six minutes. Une formule mathématique permettant de prévoir une distance de la promenade de six minutes a été générée.

Résultats: La distance moyenne de marche de six minutes \pm SD était de $590.1 \pm 72.02 \mathrm{~m}$ et était significativement plus longue chez les hommes $(p=0.001)$ chez les adolescents de 10 à 16 ans. L'âge était la seule caractéristique significativement associée à une distance de la promenade de six minutes après plusieurs analyses de régression linéaire. Les formules [distance de marche de six minutes $=317.3+21.5$ $\mathrm{x}$ l'âge (ans) chez les hommes et $117+33.0$ x l'âge (ans) chez les femmes] se rapprochent de plus ou moins de la distance mesurée à six minutes à pied.

Conclusion: Cette étude a établi des valeurs de référence pour le test de marche de 6 minutes chez des adolescents; l'utilisation de ces valeurs de référence doit tenir compte des variations d'âge et de sexe.

Mots-clés: Test d'exercice, Promenade de six minutes, Les adolescents, Nigeria

\author{
*Auteur correspondant \\ Abdulkadir, M.B. \\ http://orcid.org/0000- \\ Email address: docmohng@gmail.com \\ ${ }^{1}$ Department of Paediatrics and Child Health, University of Ilorin, Ilorin, Nigeria \\ ${ }^{2}$ Department of Paediatrics and Child Health, University of Ilorin Teaching Hospital, Ilorin, Nigeria
}




\section{INTRODUCTION}

Chronic cardiovascular and respiratory diseases are significant contributors to morbidity in children and adults (1). Conditions, such as congenital and acquired heart disease, asthma and iron deficiency anaemia have all been linked with impairment in ability of children to exercise optimally (2-4). Children with uncorrected or inoperable structural heart disease often suffer debilitating limitation in function and quality of life (5). Tests of ability to perform structured exercises provide an objective measure of degree of physical limitation from these disorders.

The 6-minute walk test (6MWT), first described by Butland et al (6) in 1982 is an alternative to the, then popular, 12-minute walk test for debilitated adults described by McGavin et al (7). The 6MWT has been shown to be a simple, safe, low cost, reliable and reproducible tool for assessing cardiorespiratory function in adults (6-8). It evaluates the global and integrated responses of the pulmonary, cardiovascular and muscular components and reflects the functional exercise level for daily physical activities (8). Several studies have demonstrated its usefulness in children and it has become part of the standard of care for the management of children with pulmonary arterial hypertension, chronic heart failure, renal disease, asthma and Duchenne muscular dystrophy, amongst others (2,9-13).

Interpretation of results of the 6MWT is dependent on the indication. In interventional studies, scores are assigned based on performance and often used to determine benefit relative to a control arm $(8,14-16)$. The alternate method for interpretation relies on comparisons of values obtained in cross sectional studies with population level standards (8). This method is most useful in establishing disease severity, prognosis and need to treat $(8-11,13)$.

Reference values and equations for children and adolescents are few. This seeming lack of data may be partially attributable to the initial consideration that values in children were widely variable and difficult to reproduce. Some described limitations of conducting the test in children include motivation and willingness to cooperate and follow instructions and have made some question its reliability $(8,12)$. However, with a better understanding of the test and stricter conditions for performing the test reproducibility is no longer a major issue and the test has severally been validated as a reliable method of testing exercise capacity in healthy children and children with cardiopulmonary disease $(9,10$, 17). Variations in children are related to age, sex, and limb length in addition to the other sources of variability related to technique (18). Thus, any reference standard for children must take into account these parameters. Several authors (1821) have determined reference standards for children in other countries, however no published studies on 6MWT reference standards for children could be found for Nigeria, and indeed, West Africa.

Thus, this study sought to determine the baseline six-minute walk distance in Nigerian adolescents aged 10-18 years and establish its relationship with age, gender and anthropometric parameters. The study also aimed to derive a mathematical formula for predicting expected six-minute walk distance in Nigerian adolescents.

\section{MATERIALS AND METHODS}

The study is a cross-sectional descriptive study of adolescents aged 10-18 years attending secondary schools in Ilorin (comprising of Ilorin West, Ilorin East and Ilorin South Local Government Areas), North-Central Nigeria. The study area is urban with an estimated population (2017) of $1,242,258$ of which adolescents constitute $22 \%$ of this population. The study was carried out in May 2017.

The study was conducted in three public secondary schools in Ilorin East, Ilorin West and Ilorin South. Ilorin has a total of 74 registered public secondary schools; all of which comprise both junior and senior secondary classes with a total student population of 28,159 as at March 2017(Source: Ministry of Education, Kwara State). There were 26 public schools in Ilorin West, 26 in Ilorin East and 22 in Ilorin South Local Government Areas. There were 7,532 students in public schools in Ilorin East, 8,624 in Ilorin South and 12,003 in Ilorin West. One public school was selected randomly from each local government area. A listing of the public schools in each LGA was made in alphabetical order of the first name and serial numbers assigned based on the listing. Selection of the school to be used in each LGA was by balloting of the assigned numbers in a box.

Sample size (N) was calculated as follows:

$$
\frac{z^{2} p(1-p)}{d^{2}}
$$

Where $\mathrm{z}$ at $99 \%$ confidence level $=2.576, \mathrm{p}=$ 0.05 (in the absence of a prevalence study) and $\mathrm{d}$ (confidence interval of $10 \%)=0.1$.

A minimum sample size of 166 was calculated. One hundred and eighty students were recruited with 60 from each of the three selected schools. A 
multistage sampling method was used in subject selection. The 60 subjects to be selected from each school were uniformly divided amongst the 6 class levels (JSS1-3, SS1-3) in each school selected with 10 pupils selected from each class level. The 10 pupils were divided to be proportionate to the pre-existing male to female ratio in each selected class. Final selection of subjects was by systematic sampling using the class list (divided into male and female) provided at study initiation.

Inclusion criteria: The criteria used were: currently a pupil enrolled in a school; age 10-18 years; consent from parents; assent from the pupil to participate in the study; and willingness to follow instructions. Children were excluded if they were in single sex schools (to avoid bias in sampling); had obvious physical deformities including visual, and limb; history to suggest preexisting respiratory or cardiovascular disease (such as recurrent/ persistent cough, easy fatigability, difficulty in breathing, cyanosis); or were ill at the time of the study.

Ethical approval: Ethical approval was obtained from the Ethical Review Committee of the University of Ilorin Teaching Hospital and permission obtained from the State Ministry of Education and school Principals. Subjects were given a consent form containing detailed information for their parents to give informed consent and assent gotten from the subjects.

\section{Data collection}

Data was collected by three data assistants. They were trained on the data collection instrument and performing the sixminute walk test, using the standard procedure as described by the American Thoracic Society (8).

An interviewer administered pretested questionnaire was used to obtain relevant demographic characteristics of subjects, including age, gender and class in school by the research assistants. Anthropometric measurements of weight, standing height, arm span, upper and lower segment length were obtained. Resting heart rate and oxygen saturations were measured after at least ten minutes of sitting calmly on a waiting chair and immediately following completion of the sixminute walk test.

Weight was measured in kilogram using a digital bathroom weighing scale (Seca model 213). Participants wore light clothing (school uniform only) without heavy jackets, cardigans, caps or hats. The weight was then taken by the recorder to the last $0.1 \mathrm{~kg}$. Standing height was measured to the nearest $0.1 \mathrm{~cm}$ using a stadiometer (Seca Model: 213, USA) with a fixed vertical backboard and an adjustable headpiece. Participants were instructed to remove caps or any hair ornaments on the top of the head and stand up straight against the backboard with the weight evenly distributed and both feet flat on the platform. Both heels were placed together and the toes apart, the head, shoulder blades, buttocks and heels made contact with the backboard. The head was then aligned in the Frankfurt horizontal plane. The headpiece was then lowered to rest firmly on the head, with sufficient pressure to compress the hair and the measurement was taken. Arm span was measured with the subject remaining in the standard position described above (see standing height measurement), with both upper limbs outstretched as far as possible to the side together and both upper limbs remaining in contact with a wall and parallel to the floor, and palms facing forwards. The tips of each middle finger (or the farthest extending finger if not middle finger) was marked along the wall and the distance between both markings measured to the nearest $0.1 \mathrm{~cm}$ using an inelastic tape. Upper segment length was taken with the subject sitting up (not slouched) on a stool (of about knee height) against a wall with both shoulders maintained at the same horizontal level, the head, shoulder blades, buttocks in firm contact with the wall and the head in the Frankfurt plane. The distance from a flatboard placed horizontally on the head to the stool was measured to the nearest $0.1 \mathrm{~cm}$. Lower segment length was determined by subtracting the standing height from the upper segment length.

The six-minute walk test was conducted according to the methodology described by the American Thoracic Society. (8)The procedure was explained to the selected students collectively to ensure uniformity of information given. They were told to avoid vigorous exercise in the two-hour period before the test was to be conducted. A hard surface on an unexposed corridor free of impediment measuring at least 30 metres was identified in the school and demarcated longitudinally with a long string held by poles at either end into two 30-metre-long walk surfaces giving a 60-metre lap on returning to the start point. A start point at the beginning of the walk surface was marked with red tape on the floor. The subjects were positioned behind a wall to avoid them seeing the distances covered by other subjects. A chair was provided for students 
that felt the need to rest at any point during the six-minute walk test. The course was marked by tapes at 3 metre intervals. The distance between the stop point and the preceding 3-metre tape was measured with a 5-metre-long inelastic measuring tape.

The subject was instructed to walk from the start point along the corridor and pivot/ turn around after each length of the corridor covering as much distance as possible over a six minute (360 seconds) period. They were asked to walk as fast a pace as they were comfortable with but not to run and were allowed to rest at any point they needed to, although the clock continued to run. The standardized words of encouragement were given at every minute ("you are doing well", "keep up the good work", "you are halfway done) by the same person in an even voice. The stopwatch and the walk were stopped, if the sixminute time was up or the subject indicated they could no longer continue and the distance covered was recorded. (8)

\section{Data analysis}

Data was analysed using SPSS version 20 software package. Frequency distribution tables and cross-tabulation of variables were generated. Mean and standard deviation for continuous variables were provided and proportion for categorical variables was also determined. Basic tests of statistical significance such as chi-square and student-t tests were utilized as required. Correlation and linear regression analyses was used to describe the relationship between the demographic/ anthropometric variables, on the one hand and the 6MWD. Anthropometric and demographic variables shown to have significant correlation with 6MWD on a univariate analysis were inserted stepwise into a multiple linear regression model to select the mix of variables that best predicted measured 6MWD. A mathematical formula for predicting 6MWD was derived from variables found to be significant independent predictors of 6MWD on the multiple linear regression analysis. A p value less than 0.05 was considered to be statistically significant.

\section{RESULTS}

One hundred and eighty subjects were recruited over a month period from the three schools with $60(33.3 \%)$ recruited from each of the Local Government Areas of Ilorin East, Ilorin West and Ilorin South.

The mean \pm SD age (years) of the subjects was $13.8 \pm 1.90$ with a range of $10-18$ years. There were 98 females $(54.4 \%)$ and 82 males $(45.6 \%)$ with a female to male ratio of 1.2:1.

The mean standing height of the subjects was $159.04 \pm 11.39 \mathrm{~cm}$. The weight, height, lower limb length, and arm span were similar between males and females (Table 1). Body mass index was significantly higher in females than males $(p=0.004)$.

The mean \pm SD 6-minute walk distance (6MWD) was 590.1 \pm 72.02 metres. Six-minute walk distance was significantly longer in males than females with mean \pm SD 6MWD of $614.1 \pm$ $62.43 \mathrm{~m}$ and $570.0 \pm 73.62 \mathrm{~m}$ respectively $(p=0.001)$. Across the age groups less than 16 years, 6MWD was significantly longer in males than females, but similar in older subjects (Table 2).

There was a strong positive correlation between 6MWD and age $(\mathrm{r}=0.73, \mathrm{p}=0.001)$; and 6MWD and height $(\mathrm{r}=0.65, \mathrm{p}=0.001)$, and $\mathrm{a}$ moderate positive correlation between 6MWD and armspan $(\mathrm{r}=0.40, \mathrm{p}=0.001)$; and 6MWD and weight $(r=0.20, p=0.008)$ and a negative correlation between 6MWD and body mass index $(\mathrm{r}=-0.25, \mathrm{p}=0.001)$.

Multiple linear regression analysis of variables related to $6 \mathrm{MWD}$ revealed age was the only significant variable amongst males and females (Table 3).

Prediction equations for 6MWD were also derived for each sex (Figure 1). They were as follows:

Males:

$6 \mathrm{MWD}($ metres $)=317.3+21.5 \mathrm{x}$ age $($ years $)$

Females:

$6 \mathrm{MWD}($ metres $)=117+33.0 \times$ age $($ years $)$

A scatter diagram showing the relationship between age and 6MWD with best fit lines for males alone, females alone and the combined population is shown in Figure 1.

\section{DISCUSSION}

This is the first study describing sixminute walk distance in Nigerian children. The test is relatively simple and has been shown to be reproducible in children (18-20,22). Its utility has been demonstrated in children with pulmonary hypertension, muscular dystrophy, and heart failure as a tool for monitoring disease severity and response to therapy $(4,9,12-14,16,17)$.

The mean 6MWD in this study of adolescents aged $10-18$ years is $590.1 \pm 72.02 \mathrm{~m}$. This is similar to $577 \pm 80 \mathrm{~m}$ reported by Iwama et al (22) from Brazil among children aged 6-16 
years. Ulrich et al (18) in Switzerland reported a mean 6MWD of $618 \pm 79$ metres among children and adolescents aged 5-17 years. Geiger et al (19) in Austria reported longer 6MWD of 697.8 \pm 74.7 metres and $725.8 \pm 61.2$ metres in male adolescents aged 12-15 years and $>16$ years respectively, and $663.0 \pm 50.8$ metres and $664.3 \pm 49.5$ metres in female adolescents aged 12-15 years and $>16$ years respectively. Thus, fairly wide variations exist in 6MWD as reported by various authors. Some of these variations may be attributable to differences in age/ height of study populations used, while some may be attributable to methodological differences. For example, the mean height of the male adolescents in our study was $160.11 \pm 11.85 \mathrm{~cm}$ compared to median heights of $166 \mathrm{~cm}$ (subjects aged 12-15 years) and $182 \mathrm{~cm}$ (subjects aged 16 years and above) in the study by Geiger et al (19). This difference was more pronounced in the female subjects. Also, Geiger et al utilized a "measuring wheel" as an intrinsic motivational device for children, compared to the other studies (including the current study) which may have improved the 6MWD achieved by subjects in their study (19). Other sources of variability in 6MWD that have been reported include differences in the population sampled, type and frequency of encouragement, corridor length and number of practice tests (8).

In the current study, 6MWD was generally longer in males than females in early and mid- adolescence in this study, but similar in the older subjects. Geiger et al (19) reported similar variations in 6MWD between male and female adolescents.

There was a significant correlation between 6MWD and most anthropometric variables in this study. In the current study, height was not a significant independent predictor of 6MWD following a multiple linear regression. This precludes the development of height based 6MWD charts or height for age charts from our data. Some earlier studies that included younger children $(<10$ years of age) have suggested height based reference values or mathematical equations should be used in determining expected 6MWD (18-21). On the other hand, studies that reported values from adolescents only (as in this study) have reported height not to be a significant independent predictor (23). This probably is a reflection of the rather narrow height spectrum in the adolescent studies compared to studies involving children from 5 to 18 years of age. Multiple linear regression analysis revealed age was a strong predictor of
6MWD in male and female subjects. Ulrich et al (18) in Switzerland and Lammers et al (20) in the United Kingdom reported similar findings of age being a strong determinant of 6MWD in children. Considering the strong correlation of 6MWD with age, age-adjusted values obtained in this study can be used as normal values for the population in this environment and distances achieved in routine clinical use may be expressed as percentage of expected for gender and age. Further studies deploying the test and the values from this study to determine their correlation with disease severity in children with cardiac or respiratory disorders will be required to determine the diagnostic utility of this interpretation for the six-minute walk test.

Several authors have reported mathematical formulae for deriving expected 6MWD in children $(18-20,24)$. The utility of these formulae lie primarily in the variations of 6MWD in children/ adolescents associated with age and anthropometrics. While some of these formulae have shown significant agreement in normal populations, there have been wide variations between others $(18-20,24)$. These wide variations question the utility of the 6MWT in children/ adolescents. However, the aforementioned variations in the methodologies of the studies in terms of age studied, population, location, and use of motivation may account for most of these variations. Thus, utilization of these values obtained in routine practice will require strict attention to the methodologies utilized in the reference studies. Furthermore, mild variations in 6MWD achieved in children with limitation of activity may be difficult to interpret, but wider variations particularly more than two standard deviations below the mean derived in this study may indicate significant limitation of activity. Larger studies in normal populations and children with cardiovascular, renal and respiratory disorders may be required in Nigeria to validate the findings of the study.

The relatively smaller sample size of this study compared to other studies in children and adolescents may constitute a limitation of this study. Nevertheless, the findings of this study provide a template for further larger studies of this simple and inexpensive test in Nigerian children and adolescents.

In conclusion, the study has generated reference ranges for estimating expected 6MWD in Nigerian adolescents aged 10-18 years and age/ gender should be taken into account in the interpretation in this environment. We recommend the routine use of the six minute walk 
test in assessing exercise capacity in adolescents in Nigeria.

Conflict of interest: The authors declare no conflict of interest.

Acknowledgements: We acknowledge the head teachers of the schools and the officials of the State Ministry of Education for their support in conducting this study.

\section{REFERENCES}

1. Lim SS, Vos T, Flaxman AD, Danaei G, Shibuya $\mathrm{K}$, Adair-Rohani $\mathrm{H}$ et al. A comparative risk assessment of burden of disease and injury attributable to 67 risk factors and risk factor clusters in 21 regions, 1990-2010: a systematic analysis for the Global Burden of Disease Study 2010. The Lancet 2012;380(9859):2224-60.

2. Allen HD, Driscoll DJ, Shaddy RE, Feltes TF. Moss \& Adams' Heart Disease in Infants, Children, and Adolescents: Including the Fetus and Young Adult. 8th ed. Philadelphia: Lippincott Williams \& Wilkins, 2013.

3. Lozoff B, Jimenez E, Wolf AW. Long-Term Developmental Outcome of Infants with Iron Deficiency. NEJM 1991;325(10):687-94.

4. Juniper EF, Guyatt GH, Feeny DH, Ferrie P, Griffith LE, Townsend M. Measuring quality of life in children with asthma. Qual Life Res 1996;5(1):35-46.

5. Cohen M, Mansoor D, Langut H, Lorber A. Quality of life, depressed mood, and self-esteem in adolescents with heart disease. Psychosom Med 2007;69(4):313-18.

6. Butland RJ, Pang J, Gross ER, Woodcock AA, Geddes DM. Two-, six-, and 12-minute walking tests in respiratory disease. Br Med J (Clin Res Ed) 1982;284(6329):1607-08.

7. McGavin CR, Gupta SP, McHardy GJ. Twelveminute walking test for assessing disability in chronic bronchitis. BMJ 1976;1(6013):822-23.

8. ATS statement: guidelines for the six-minute walk test. Am J Respir Crit Care Med 2002;166(1):1117.

9. Watanabe FT, Koch VHK, Juliani RCTP, Cunha MT. Six-minute walk test in children and adolescents with renal diseases: tolerance, reproducibility and comparison with healthy subjects. Clinics 2016;71:22-27.

10. Andrade LBd, Silva DARG, Salgado TLB, Figueroa JN, Lucena-Silva N, Britto MCA. Comparison of six-minute walk test in children with moderate/severe asthma with reference values for healthy children. J Pediatr (Rio J) 2014;90(3):250-57.

11. Galiè N, Hoeper MM, Humbert M, Torbicki A, Vachiery J-L, Barbera JA et al. Guidelines for the diagnosis and treatment of pulmonary hypertension. The Task Force for the Diagnosis and Treatment of Pulmonary Hypertension of the
European Society of Cardiology (ESC) and the European Respiratory Society (ERS), endorsed by the International Society of Heart and Lung Transplantation (ISHLT). Eur Heart J 2009;30(20):2493-537.

12. Rhodes J, Ubeda Tikkanen A, Jenkins KJ. Exercise Testing and Training in Children With Congenital Heart Disease. Circulation 2010;122(19):1957-67.

13. McDonald CM, Henricson EK, Han JJ, Abresch RT, Nicorici A, Elfring GL et al. The 6-minute walk test as a new outcome measure in Duchenne muscular dystrophy. Muscle Nerve 2010;41(4):500-10.

14. Hoeper M, Taha N, Bekjarova A, Gatzke R, Spiekerkoetter E. Bosentan treatment in patients with primary pulmonary hypertension receiving nonparenteral prostanoids. Eur Respir J 2003;22(2):330-34.

15. Olsson LG, Swedberg K, Clark AL, Witte KK, Cleland JG. Six minute corridor walk test as an outcome measure for the assessment of treatment in randomized, blinded intervention trials of chronic heart failure: a systematic review. Eur Heart J 2005;26(8):778-93.

16. Galiè N, Rubin L, Hoeper M, Jansa P, Al-Hiti H, Meyer G et al. Treatment of patients with mildly symptomatic pulmonary arterial hypertension with bosentan (EARLY study): a double-blind, randomised controlled trial. The Lancet 2008;371(9630):2093-100.

17. Morinder G, Mattsson E, Sollander C, Marcus C, Larsson UE. Six-minute walk test in obese children and adolescents: Reproducibility and validity. Physiother Res Int 2009;14(2):91-104.

18. Ulrich S, Hildenbrand FF, Treder U, Fischler M, Keusch S, Speich R et al. Reference values for the 6-minute walk test in healthy children and adolescents in Switzerland. BMC Pulm Med 2013;13(1):49.

19. Geiger R, Strasak A, Treml B, Gasser K, Kleinsasser A, Fischer V et al. Six-Minute Walk Test in Children and Adolescents. J Pediatr 2007;150(4):395-99.e2.

20. Lammers AE, Hislop AA, Flynn Y, Haworth SG. The 6-minute walk test: normal values for children of 4-11 years of age. Arch Dis Child 2008;93(6):464-68.

21. Li AM, Yin J, Au JT, So HK, Tsang T, Wong E et al. Standard Reference for the Six-Minute-Walk Test in Healthy Children Aged 7 to 16 Years. Am J Respir Crit Care Med 2007;176(2):174-80.

22. Iwama AM, Andrade GN, Shima P, Tanni SE, Godoy I, Dourado VZ et al. The six-minute walk test and body weight-walk distance product in healthy Brazilian subjects. Braz J Med Biol Res 2009;42:1080-85.

23. Kanburoglu MK, Ozdemir FM, Ozkan S, Tunaoglu FS. Reference Values of the 6-Minute Walk Test in Healthy Turkish Children and Adolescents Between 11 and 18 Years of Age. Respir Care 2014;59(9):1369 
24. Priesnitz CV, Rodrigues GH, da Silva Stumpf C, Viapiana G, Cabral CP, Stein RT et al. Reference values for the 6-min walk test in healthy children aged 6-12 years. Pediatr Pulmonol 2009;44(12):1174-79. 
Table 1: Anthropometric parameters across gender groups of the subjects

\begin{tabular}{lllll}
\hline Anthropometric parameter & $\begin{array}{l}\text { Males } \\
\mathbf{N = 8 2}\end{array}$ & $\begin{array}{l}\text { Females } \\
\mathbf{N = 9 8}\end{array}$ & $\mathbf{t}$ & $\mathbf{p}$ \\
& $46.91 \pm 10.75$ & $49.46 \pm 11.59$ & -1.521 & 0.130 \\
Mean \pm SD Weight $(\mathrm{Kg})$ & $160.11 \pm 11.85$ & $158.14 \pm 10.97$ & 1.158 & 0.248 \\
Mean \pm SD Height $(\mathrm{cm})$ & $83.59 \pm 8.13$ & $81.85 \pm 6.17$ & 1.599 & 0.112 \\
Mean \pm SD Lower limb length $(\mathrm{cm})$ & $168.01 \pm 15.61$ & $166.25 \pm 9.18$ & 0.900 & 0.370 \\
Mean \pm SD Arm span $(\mathrm{cm})$ & $18.20 \pm 3.67$ & $19.69 \pm 3.77$ & -2.674 & 0.008 \\
Mean \pm SD Body mass index & & & & \\
\hline
\end{tabular}

Table 2: Six-minute walk distance of subjects by age group

\begin{tabular}{llllll}
\hline Age group & Frequency & $\begin{array}{l}\text { Mean } \pm \text { SD 6MWD in } \\
\text { males }(\mathbf{n})\end{array}$ & $\begin{array}{l}\text { Mean } \pm \text { SD 6MWD in } \\
\text { females (n) }\end{array}$ & t & P \\
\hline $10-12$ years & 45 & $545.2 \pm 53.26(20)$ & $491.3 \pm 55.79(25)$ & 3.286 & 0.002 \\
$13-15$ years & 101 & $627.3 \pm 35.91(43)$ & $580.6 \pm 43.84(58)$ & 5.714 & 0.000 \\
$16-18$ years & 34 & $656.9 \pm 62.48(19)$ & $660.5 \pm 63.89(15)$ & -0.165 & 0.870 \\
\hline
\end{tabular}

Table 3: Linear regression analysis of factors related to six-minute walk distance by gender

\begin{tabular}{lllllll}
\hline & Males & \multicolumn{7}{c}{ Females } \\
\hline & $\begin{array}{l}\text { Unstandardized } \\
\text { coefficient }\end{array}$ & S.E & $\mathrm{p}$ & $\begin{array}{l}\text { Unstandardized } \\
\text { coefficient }\end{array}$ & S.E & $\mathrm{p}$ \\
\hline Age & 13.36 & 4.36 & 0.003 & 29.14 & 3.69 & 0.000 \\
Height & 1.68 & 2.16 & 0.440 & -0.25 & 2.06 & 0.904 \\
Arm span & 0.54 & 0.60 & 0.366 & 0.55 & 0.64 & 0.388 \\
BMI & -1.79 & 7.14 & 0.803 & -5.72 & 8.24 & 0.489 \\
Weight & -1.04 & 3.24 & 0.748 & 1.16 & 3.20 & 0.718 \\
\hline
\end{tabular}




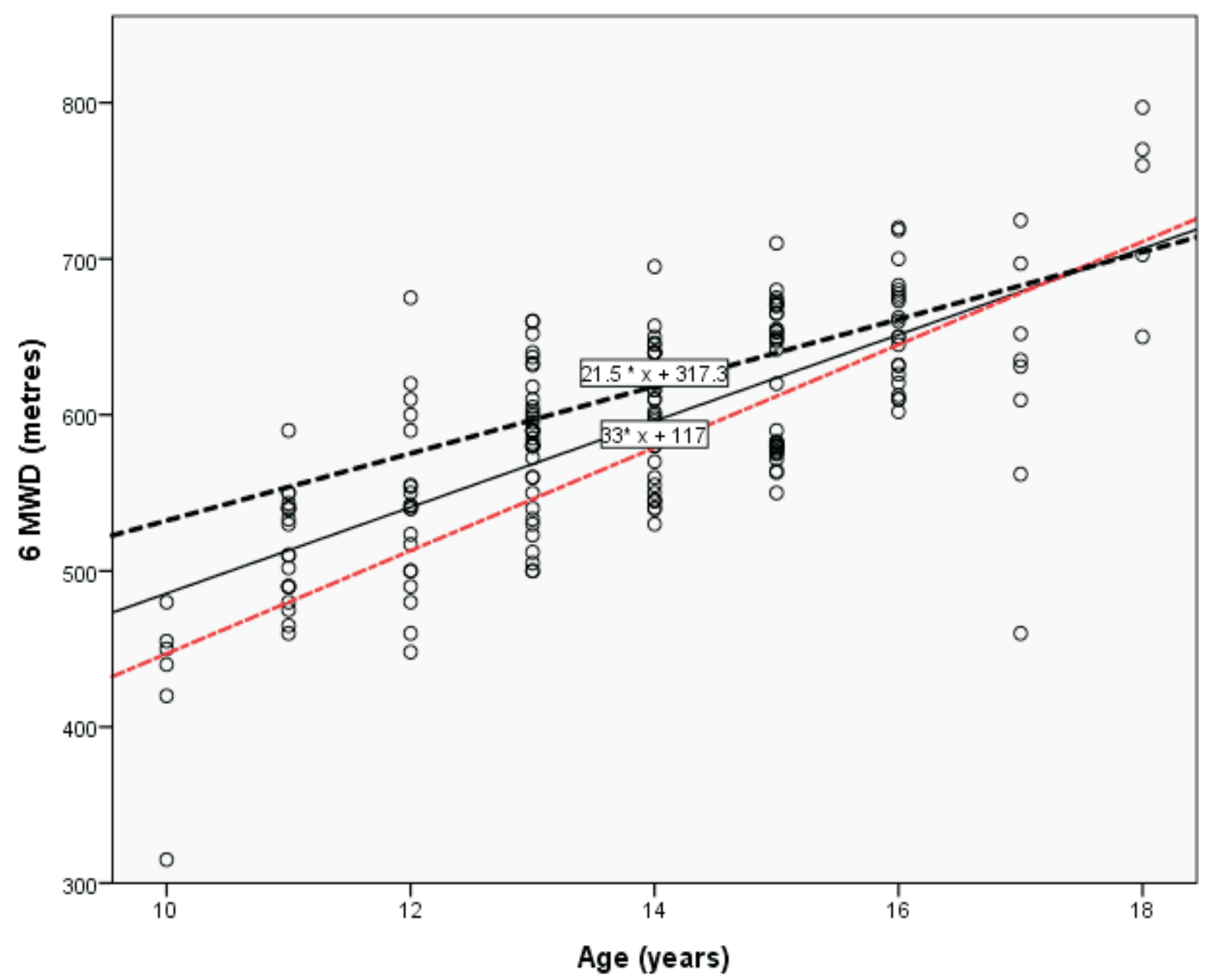

Figure 1: Scatter plot and best fit lines for six-minute walk distance of male subjects (black dashed line), female subjects (red dashed line) and all the subjects combined (solid line) 